\title{
Camera-Based Parking System Management Using Raspberry Pi
}

\author{
Ahmad Zatnika Purwalaksana ${ }^{1 a)}$, Dewi Siburian ${ }^{1}$, Immanuel Sianturi ${ }^{1}$, dan \\ Sabam Sianturi ${ }^{1}$
}

${ }^{1}$ Teknologi Komputer, Institut Teknologi Del, Sitoluama, Toba, Indonesia- 22381

E-mail: a)ahmad.purwalaksana@del.ac.id

\begin{abstract}
Abstrak: Saat ini masih banyak penggunaan sistem parkir manual, yaitu petugas parkir memberikan instruksi untuk kendaraan melakukan parkir. Hal ini sering dianggap kurang efisien karena tidak adanya pencatatan data kendaraan yang melakukan parkir sehingga mengakibatkan rendahnya tingkat keamanan dan kenyamanan bagi pengunjung serta sistem parkir tidak menyediakan informasi mengenai slot parkir yang dapat menyulitkan pengunjung dalam melakukan parkir kendaraan. Dengan hal ini maka kendaraan yang hendak parkir seringkali mengalami kesulitan ketika akan melakukan parkir kendaraan. Melalui berbagai permasalahan yang terjadi, penulis mengembangkan sebuah sistem parkir yang dapat memberikan informasi ketersediaan slot parkir pada area parkir serta penyimpanan data plat nomor kendaraan yang melakukan parkir. Pada sistem parkir digunakan Raspberry Pi 3 Model B sebagai pengontrol utama, deteksi kamera untuk mendapatkan informasi berupa karakter dari plat nomor kendaraan dengan bantuan OCR (Optical Character Recognition), penggunaan kode OTP (One Time Password) yang dapat dipergunakan satu kali saja sehingga meningkatkan kemanan pada sistem parkir. Data kendaraan berupa plat nomor dan juga kode OTP akan disimpan dalam database dan digunakan ketika kendaraan akan keluar dari area parkir dengan melakukan pencocokan data plat nomor dan kode OTP dari sebuah kendaraan untuk dapat meninggalkan area parkir. Melalui pembangunan sistem parkir diharapkan dapat berjalan dengan baik bagi pengemudi kendaraan untuk menemukan lokasi parkir yang tersedia serta meningkatkan keamanan dan kenyamanan bagi pengemudi karena adanya penyimpanan data berupa plat nomor kendaraan sebagai identitas kendaraan serta penggunaan kode OTP yang hanya dapat digunakan satu kali saja.
\end{abstract}

Kata kunci: Raspberry Pi 3 Model B, OCR (Optical Character Recognition), sistem parkir, kamera, keamanan, dan informasi slot parkir.

Abstract: Currently, there are still many use of manual parking systems, namely parking attendants provide instructions for vehicles to park. This is often considered inefficient because there is no data recording of vehicles that park, resulting in a low level of security and comfort for visitors and the parking system does not provide information about parking slots which can make it difficult for visitors to park vehicles. With this, the vehicle that wants to park often has difficulty when parking the vehicle. Through various problems that occur, the author develops a parking system that can provide information on the availability of parking slots in the parking area as well as data storage for vehicle number plates that do parking. In the parking system, the Raspberry Pi 3 Model B is used as the main controller, camera detection to obtain information in the form of characters from the vehicle number plate with the help of OCR (Optical Character Recognition), the use of OTP (One Time Password) code which can be used only once so as to increase security. on the parking system. Vehicle data in the form of number plates and also OTP code will be stored in the database and used when the vehicle will leave the parking area by matching the number plate data and OTP code of a vehicle to be able to leave the parking area. Through the development of the parking system, it is hoped that it will work well for vehicle drivers to find available parking locations and increase safety and comfort for drivers because of data storage in the form of vehicle number plates as vehicle identity and the use of OTP codes that can only be used once.

Keywords: Raspberry Pi 3 Model B, OCR (Optical Character Recognition), parking system, camera, security and parking slot information. 


\section{PENDAHULUAN}

Kepadatan penduduk serta tingkat ekonomi yang tinggi menyebabkan tingginya tingkat kepemilikan kendaraan pribadi. Melalui hasil sensus Badan Pusat Statistik dinyatakan bahwa jumlah kendaraan bermotor di Indonesia mencapai 133 juta pada 2019. Data tersebut terangkum dalam catatan Badan Pusat Statistik (BPS). Terdapat peningkatan pada tahun 2019 sebesar 7.108.236 kendaraan dari 126.508.776 kendaraan sedangkan pada tahun 2018 peningkatan sebesar 5,3\% menjadi 133.617.012 kendaraan. Jika situasi ini didukung oleh kebijakan manajemen lalu lintas pemerintah yang tidak membatasi penggunaan kendaraan pribadi, maka akan mendukung masyarakat untuk selalu menggunakan kendaraan pribadi. Hal ini akan mengakibatkan kebutuhan akan lahan parkir yang luas.

Saat ini sistem parkir secara manual masih banyak digunakan dengan petugas parkir mengarahkan setiap kendaraan yang akan melakukan parkir pada lokasi parkir. Sistem parkir secara manual kurang efektif karena memiliki kelemahan yaitu tidak adanya pencatatan data kendaraan yang melakukan parkir pada area tersebut serta mengakibatkan rendahnya tingkat keamanan serta kenyamanan untuk pemilik alat transportasi. Penggunaan area parkir pada pusat perbelanjaan seperti mall juga sering dijumpai permasalahan karena informasi ketersediaan lahan parkir yang tidak tersedia sehingga menyebabkan antrian panjang [1]. Sistem parkir pada apartemen juga sering mengalami kendala yang sama yaitu kurangnya informasi mengenai ketersediaan slot parkir sehingga pemilik transportasi memerlukan waktu yang tidak sedikit dalam mendapatkan lahan parkir yang belum terisi [2].

Pada area parkir manual terdapat juga kendala berupa keamanan yang kurang memadai, seperti adanya kemungkinan melakukan pencurian kendaraan pada lokasi parkir karena tidak adanya identitas sebagai pedoman petugas parkir dalam melakukan penjagaan kendaraan. Timbulnya permasalahan parkir memerlukan pemahaman mengenai konsep dari lahan parkir, kebutuhan parkir, dan kebijakan parkir merupakan materi yang dapat diterapkan untuk menangani permasalahan parkir.

Melalui permasalahan di atas, maka dilakukan analisis dalam menemukan solusi terhadap penggunaan lahan parkir sehingga melalui pembangunan sistem diharapkan dapat menjadi jalan keluar dari persoalan yang dialami. Dengan adanya pencatatan informasi berupa data kendaraan yang melakukan parkir, keamanan kendaraan pada sistem parkir akan lebih baik. Melalui proses ini, dibangun sistem parkir dengan menggunakan kamera untuk melakukan identifikasi pada kendaraan yaitu berupa plat nomor dari kendaraan yang menjadi sebuah identitas bagi sebuah kendaraan karena setiap kendaraan memiliki plat nomor yang berbeda [3] serta memberikan informasi terhadap pengunjung mengenai ketersediaan slot parkir yang mempermudah pengunjung dalam menemukan slot parkir kendaraan. Namun, sistem yang telah dibangun masih berbentuk model atau sering disebut sebagai prototipe.

\section{METODOLOGI}

Dalam mengatasi masalah dari pembangunan sistem parkir yang telah berjalan secara manual saat ini, pengembang memanfaatkan pengambilan citra gambar melalui kamera berupa karakter dari plat nomor kendaraan yang kemudian di-input dalam database sebagai salah satu identitas dari kendaraan tersebut. Pada tahap ini juga dilakukan pemanfaatan qr code yang akan dipindai dengan menggunakan smartphone yang dimiliki pengemudi kendaraan. Metode qr code dapat digunakan dalam banyak hal termasuk untuk keamanan data atau menjaga keaslian produk [4]. Melalui qr code yang telah dipindai oleh pengemudi kendaraan, maka smartphone akan terhubung pada website sistem parkir yang telah dikembangkan untuk memberikan informasi berupa kode OTP dan slot parkir yang telah berisi dan masih kosong pada halaman website sistem parkir. Metode One Time Password (OTP) adalah kata sandi yang valid (absah) dan dapat digunakan hanya untuk satu kali sesi login atau transaksi saja pada komputer atau alat digital lainnya [5]. OTP biasanya digunakan sebagai mekanisme otentikasi tambahan untuk itu OTP sering disebut sebagai dua faktor otentikasi (two-factor authentication atau second factor authentication) [6]. Penelitian mengenai Metode OTP yang telah dilakukan, terdiri dari beberapa kasus antara lain dalam implementasi terhadap keamanan e-commerce [7]. Kode OTP dan plat nomor akan disimpan di database untuk dilakukan pencocokan data ketika kendaraan akan keluar dari area parkir. Setelah proses tersebut selesai, palang parkir akan terbuka dan pengemudi dapat melakukan parkir kendaran pada slot parkir yang masih tersedia berdasarkan informasi dari website sistem parkir. 
Pada implementasi slot parkir, digunakan kode program yang berisikan modul atau library dari openCV (Open Computer Vision) dalam menampilkan bentuk tangkapan video dari kamera yang digunakan. OpenCV adalah salah satu pustaka dari computer vision yang merupakan sebuah API (Application Programming Interface) dengan library yang sudang sangat familiar pada pengolahan citra computer vision [8]. Digunakan fungsi perulangan dalam pengambilan data video serta disimpan dalam array variabel dengan format warna bgr untuk mengubah citra gambar menjadi keabuan. Hal ini dilakukan untuk lebih mudah dalam pendeteksian karakter, kemudian akan dilanjut dengan perintah threshold yang merupakan sebuah metode segmentasi yang digunakan untuk memisahkan objek dengan background dalam suatu citra dengan perbedaan tingkat kegelapan dan kecerahannya sehingga dengan rangkaian proses ini karakter dapat ditangkap oleh kamera dengan bantuan ocr (Optical Character Recognition) dengan baik. Frame yang ditampilkan pada slot parkir sebanyak 3 frame yang dalam prototipe area parkir dinamakan slot parkir yang dapat dibedakan sesuai dengan posisi atau letak slot pada lokasi parkir. Dengan penggunaan fungsi frame, maka posisi dalam slot parkir dapat dideteksi sehingga informasi ketersediaan slot parkir kendaraan dapat diperbarui.

Ketika pengemudi akan membawa kendaraan keluar dari area parkir maka kendaraan menuju pintu keluar area parkir. Kemudian dilakukan pengambilan gambar dengan citra kamera dengan bantuan OCR (Optical Character Recognition) dalam mendapatkan karakter plat nomor dari kendaraan. Optical Character Recognition (OCR) adalah proses yang dapat mengkonversi gambar yang berisikan teks menjadi karakter ASCII yang dapat dikenali oleh komputer [9]. Pada saat ini implementasi OCR dipermudah dengan adanya library Tesseract OCR dan tingkat akurasinya juga tergolong tinggi [10]. Setelah karakter plat didapatkan, monitor akan menampilkan qr code yang akan dipindai oleh pengemudi kendaraan dengan menggunakan smartphone pribadi. Melalui qr code yang telah dipindai oleh pengemudi kendaraan tersebut, akan ditampilkan website sistem parkir, dimana pengemudi kendaraan harus mengisi kode OTP yang telah diberikan pada awal ketika kendaraan memasuki area parkir. Setelah itu dilakukan pencocokan data antara plat nomor kendaraan dengan kode OTP. Jika pengemudi kendaraan melakukan pengisian kode OTP dengan benar maka palang parkir terangkat sehingga kendaraan dapat meninggalkan area parkir dan apabila kode OTP yang diisi oleh pengemudi kendaraan tidak tepat maka palang parkir tidak terangkat serta kendaraan tidak dapat meninggalkan area parkir.

\section{HASIL DAN PEMBAHASAN}

\section{Implementasi}

Implementasi hardware dan software yang digunakan dalam pengimplementasian sistem sesuai dengan rancangan yang telah dibuat sebelumnya. Tahap implementasi yang digunakan berupa proses instalasi software, konfigurasi dan pengujian terhadap software serta hardware yang digunakan. Pada implementasi prototipe lahan parkir, digunakan prototipe lahan seperti gambar 1 di bawah.

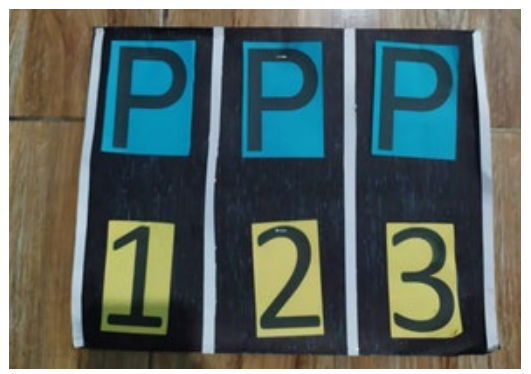

Gambar 1. Prototipe lahan parkir

Pada implementasi sistem parkir, kamera diletakkan di depan slot parkir dengan posisi yang tetap dapat dilihat melalui gambar 2 dengan tujuan agar dapat memberikan informasi berupa lahan parkir yang jelas. Melalui pola prototipe lahan parkir diatas dapat dilakukan pendeteksian lahan parkir yang kosong dan yang telah berisi. Apabila terdapat halangan yang menutupi slot parkir tersebut maka slot parkir akan dideteksi telah berisi pada website dengan keterangan angka 1 pada website, demikian juga sebaliknya yaitu jika tidak ada yang menghalangi pola pada slot parkir tersebut maka dideteksi tidak berisi atau kosong dengan keterangan angka 0 pada database website. 


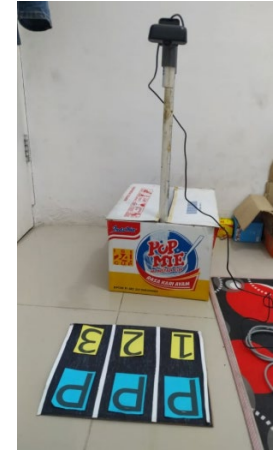

Gambar 2. Posisi kamera pada lokasi parkir

Melalui pola slot parkir yang telah dirancangkan, maka ketersediaan slot parkir akan mengalami pembaruan pada website. Sehingga jika belum mendeteksi adanya kendaraan pada slot parkir akan diartikan bahwa lahan parkir tersebut masih kosong dan jika terdeteksi adanya kendaraan akan diartikan bahwa lahan parkir tersebut telah berisi. Pemberian informasi slot parkir diimplementasikan dapat dilihat pada gambar 3.

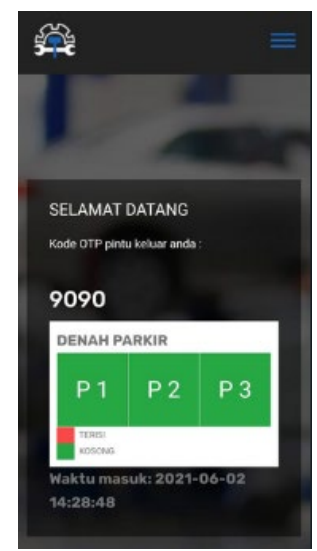

Gambar 3. Atar muka website ketersediaan slot parkir pada sistem parkir

Dalam melakukan pendeteksian plat nomor kendaraan pada prototipe area parkir, kamera yang telah dihubungkan dengan raspberry pi dilengkapi dengan OCR agar dapat mengolah gambar plat nomor kendaraan menjadi karakter. Hal ini bertujuan agar plat nomor kendaraan dapat disimpan dalam database sistem parkir demi mengingkatkan keamanan dalam area parkir yang diimplementasikan.

Dalam melakukan pendeteksian plat nomor, ketika kendaraan akan memasuki area parkir maka kamera akan menangkap gambar plat nomor kendaraan seperti gambar 4. Setelah itu hasil pengamatan plat nomor kendaraan seperti gambar 5 kemudian diubah menjadi karakter agar dapat disimpan dalam database.

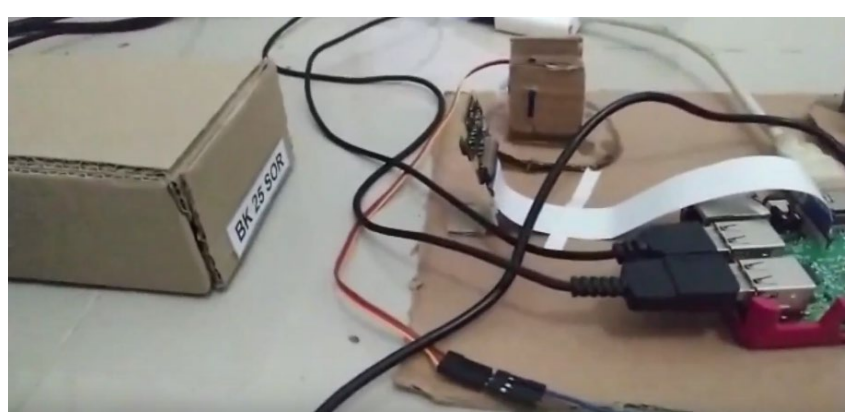

Gambar 4. Tata letak penangkapan data plat nomor kendaraan. 


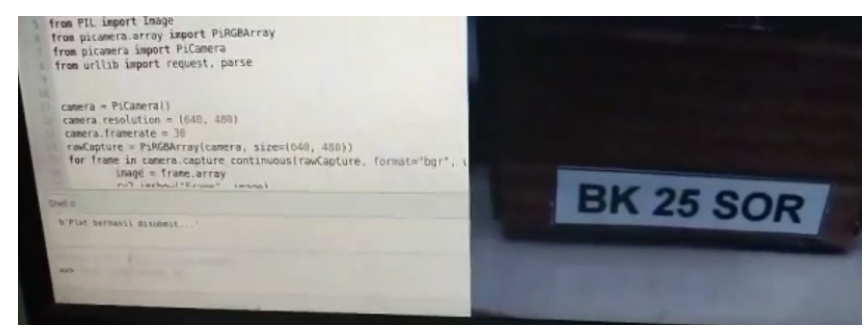

Gambar 5. Hasil deteksi plat nomor kendaraan

Pada sistem yang dibangun, kamera digunakan untuk mengambil gambar berupa slot parkir pada prototipe area parkir yang telah disediakan ditempatkan pada posisi yang tetap seperti pada gambar 4.6. Hal ini bertujuan agar para pengunjung dapat menerima informasi berupa slot parkir yang kosong dan telah terisi pada website yang telah disediakan. Berdasarkan lahan parkir tersebut, maka informasi ketersediaan slot parkir ditampilkan pada antar muka berupa website seperti gambar 6 .

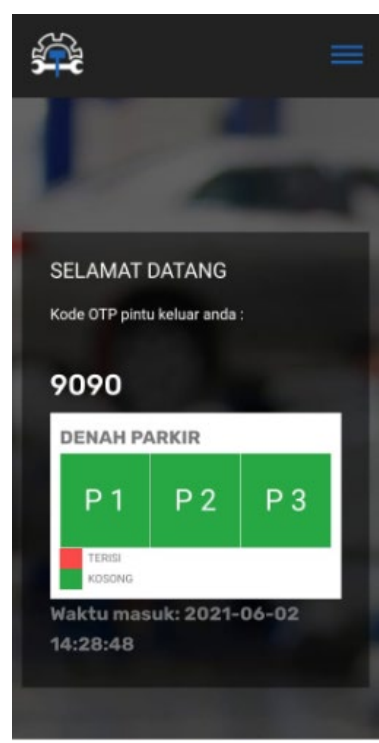

Gambar 6. Informasi ketersediaan lahan parkir pada website

Pada pintu masuk area parkir akan dilakukan pengambilan data berupa plat nomor kendaraan yang digunakan sebagai identitas dari kendaraan tersebut yang kemudian disimpan dalam database seperti pada gambar 7 di bawah. Plat nomor yang telah dideteksi oleh kamera akan diubah menjadi karakter dengan penggunaan OCR (Optical Character Recognition) dan disimpan dalam database yang juga berelasi terhadap kode OTP yang diberikan pada masing-masing pemilik kendaraan dengan menggunakan antar muka berupa website sistem parkir yang dapat diakses dengan melakukan pemindaian terhadap qr code pada layar monitor sistem parkir. 


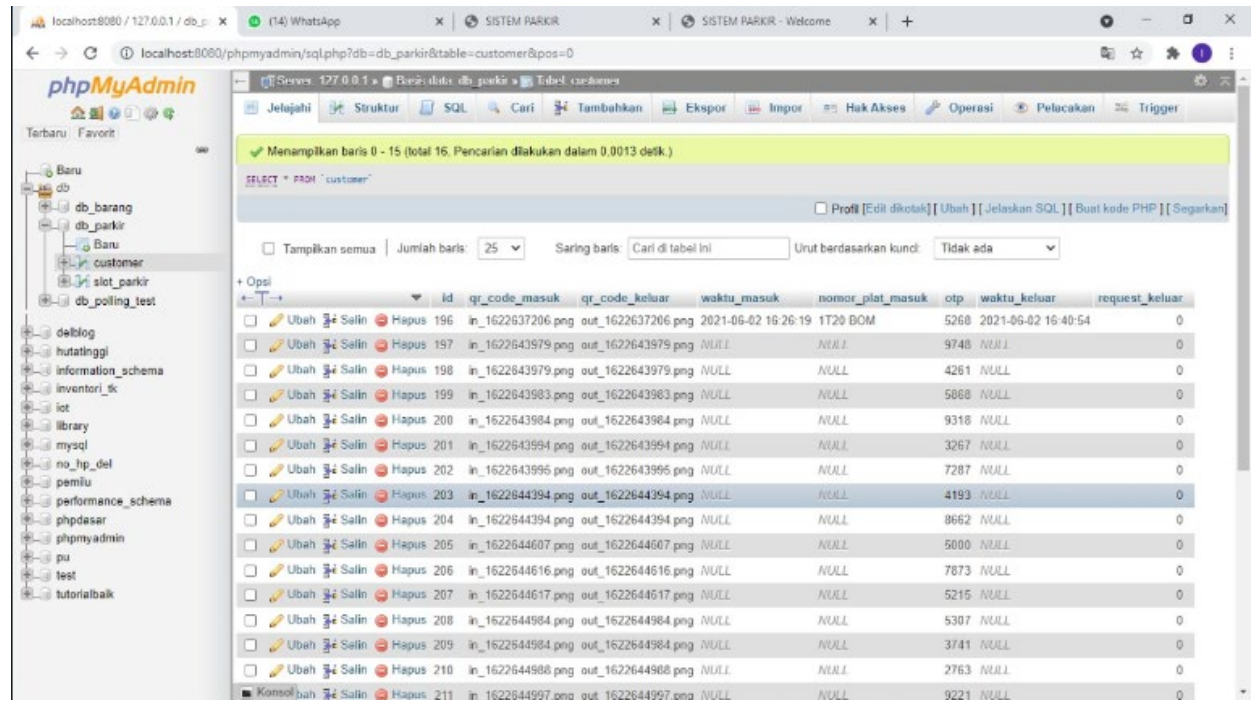

Gambar 7. Database sistem parkir

Website pada sistem ini digunakan sebagai pemberi informasi mengenai ketersediaan lahan parkir terhadap pengunjung dengan tujuan untuk mempermudah pengunjung dalam menemukan slot parkir. Website ini juga memiliki pengolahan data untuk dapat menyimpan data kendaraan yang melakukan parkir pada area tersebut berupa data statistik pengunaan lahan parkir.

Alur penyimpanan data pada sistem parkir ini dilakukan pada raspberry pi sebagai otak dari sistem yang dibangun yang dapat melakukan penangkapan plat nomor kendaraan oleh kamera yang terhubung pada raspberry. Setelah data diperoleh, maka akan disimpan dalam database. Kemudian dalam menampilkan data pada website, browser akan melakukan request pada database yang kemudian akan diolah pada website.Tampilan website ditunjukan pada gambar 8 .

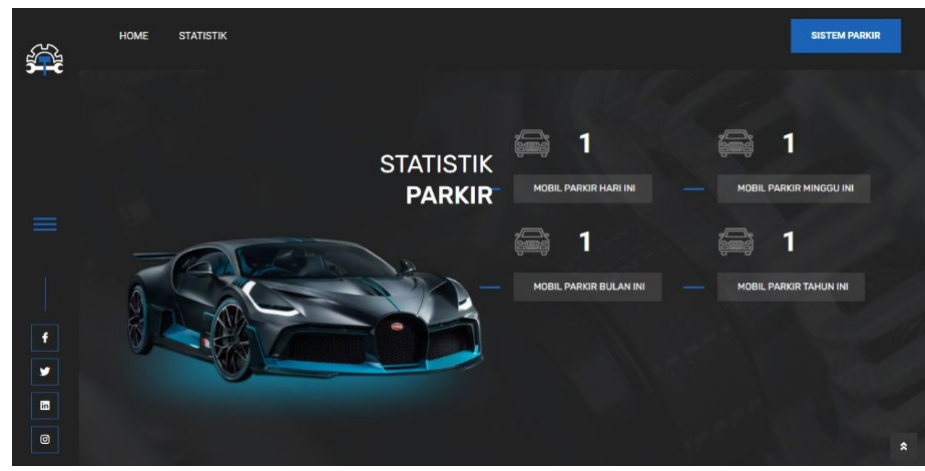

Gambar 8. Tampilan website berisi statistik parkir 


\section{Pengujian}

Pada subbab ini berisi penjelasan mengenai cara kerja raspberry pi dan kamera. Ketika program pengambilan karakter plat nomor dijalankan maka akan muncul kerangka dalam melakukan penangkapan gambar oleh kamera. Hasil dari tangkapan kamera tersebut adalah plat nomor kendaraan yang akan melakukan parkir. Gambar yang telah diambil oleh kamera akan diproses dengan tesseract OCR untuk dikonversi dalam bentuk karakter dan disimpan dalam database.

\subsection{Pengujian terhadap Kamera}

Pada sistem parkir yang dibangun ada 2 fungsi kamera yang digunakan yaitu sebagai berikut:

\subsubsection{Pengujian Kamera pada Deteksi Plat Nomor}

Pengujian terhadap kamera digunakan untuk dapat melihat apakah kamera dapat digunakan dan melakukan fungsinya dengan baik yaitu untuk menangkap gambar berupa plat nomor kendaraan serta mengubahnya menjadi karakter dengan bantuan tesseract OCR (Optical Character Recognition). Pengujian ini dilakukan dengan jarak cukup kecil yaitu dalam satuan cm (centi meter) karena implementasi dari sistem parkir yang dibangun masih dalam bentuk prototipe dengan hasil pengujian seperti berikut:

Hasil uji penggunaan kamera untuk melakukan pendeteksian plat nomor kendaraan dilampirkan pada tabel 1.

Tabel 1. Pengujian jarak kamera

\begin{tabular}{|l|l|l|}
\hline No & Jarak & Keterangan \\
\hline 1. & $15 \mathrm{~cm}$ & Berhasil \\
\hline 2. & $22 \mathrm{~cm}$ & Berhasil \\
\hline 3. & $30 \mathrm{~cm}$ & Berhasil \\
\hline 4. & $37 \mathrm{~cm}$ & Tidak Berhasil \\
\hline
\end{tabular}

Melalui tabel 1 dapat kita simpulkan bahwa kamera dapat mengambil gambar dengan jarak lebih kecil dari $30 \mathrm{~cm}$. Ketika kamera telah bekerja, maka pada database akan dimasukkan data berupa karakter dari plat nomor kendaraan ke dalam database sebagai penyimpanan data sistem parkir. Hasil dari konversi file gambar dikonversi menjadi karakter dengan bantuan OCR. Kemudian data plat nomor kendaraan akan di-input dalam database.

\subsubsection{Pengujian Kamera pada Deteksi Slot Parkir}

Pengujian terhadap kamera digunakan untuk dapat melihat apakah kamera dapat digunakan dan melakukan deteksi ketersediaan slot parkir pada prototipe area parkir dengan menangkap gambar yang dilakukan webcam yang terhubung pada raspberry pi.

\subsection{Pengujian terhadap QR Code}

Dalam proses pengujian keberhasilan pemindaian qr code, pengemudi akan melakukan pemindaian qr code yang telah ditampilkan pada layar monitor pada prototipe sistem parkir kendaraan agar mendapatkan informasi berupa slot parkir yang tersedia dan kode OTP yang digunakan ketika akan keluar dari area parkir, maka dalam setiap proses pengujian dilakukan dengan jarak yang berbeda. Jarak pengujian yang dilakukan dalam satuan yang cukup kecil yaitu cm (centi meter) dikarenakan implementasi sistem parkir masih dalam bentuk prototipe dalam melakukan pemindaian terhadap qr code. Hasil pengujian terhadap pemindaian qr code ditunjukkan pada tabel 2.

Tabel 2. Pengujian qr code

\begin{tabular}{|l|l|l|}
\hline No & Jarak & Keterangan \\
\hline 1. & $20 \mathrm{~cm}$ & Berhasil \\
\hline 2. & $35 \mathrm{~cm}$ & Berhasil \\
\hline 3. & $55 \mathrm{~cm}$ & Berhasil \\
\hline 4. & $70 \mathrm{~cm}$ & Tidak Berhasil \\
\hline
\end{tabular}

Melalui tabel 2 diatas, dapat diketahui bahwa sistem yang dibangun dapat mengikuti standar keberhasilan dalam membaca kode qr pada layar monitor oleh pengemudi setiap kendaraan dengan jarak lebih kecil dari $70 \mathrm{~cm}$ dari kamera. Jarak yang cukup kecil ini dapat dimaanfaatkan karena pembangunan sistem parkir masih dalam tahap pemodelan atau prototipe. 


\subsection{Pengujian Kondisi Kendaraan}

Ketika sebuah kendaraan ingin memasuki area parkir maka kendaraan menuju pintu masuk area parkir. Dalam memasuki area parkir hanya disediakan sebuah pintu masuk dan pintu keluar pada prototipe area parkir. Ketika kendaraan akan memasuki area parkir ada kemungkinan kendaraan untuk menunggu kendaraan lain yang terlebih dahulu akan memasuki area parkir, untuk itu dilakukan proses antri pada pintu masuk area parkir. Pada keadaaran ini kendaraan dapat berhenti sejenak untuk melakukan pemindaian qr code dengan kondisi mesin kendaraan mati atau masih berjalan.

Kondisi monitor pada pintu masuk area parkir selalu siap, ketika ada sebuah kendaraan yang akan memasuki area parkir maka raspberry pi camera module akan menangkap informasi berupa plat nomor kendaraan yang akan disimpan pada database sistem parkir. Bersamaan dengan proses tersebut ditampilkan qr code pada layar monitor sistem parkir untuk dilakukan pemindaian dengan menggunakan smartphone milik pengemudi kendaraan.

\subsection{Pengujian Masuk Area Parkir}

Ketika kendaraan akan memasuki area parkir ada beberapa hal yang harus dilakukan oleh pengemudi sebelum melakukan parkir kendaraan pada prototipe lahan parkir. Melalui hal tersebut, berikut hasil pengujian slot parkir pada sistem parkir yang telah dibangun.

\subsubsection{Pengujian 1 kendaraan memasuki area parkir}

Hal pertama yang dilakukan pengemudi adalah membawa kendaraan pada pintu masuk area parkir. Pada pintu masuk, tampilan monitor sesuai dengan gambar 9 yang menampilkan qr code pada layar monitor.

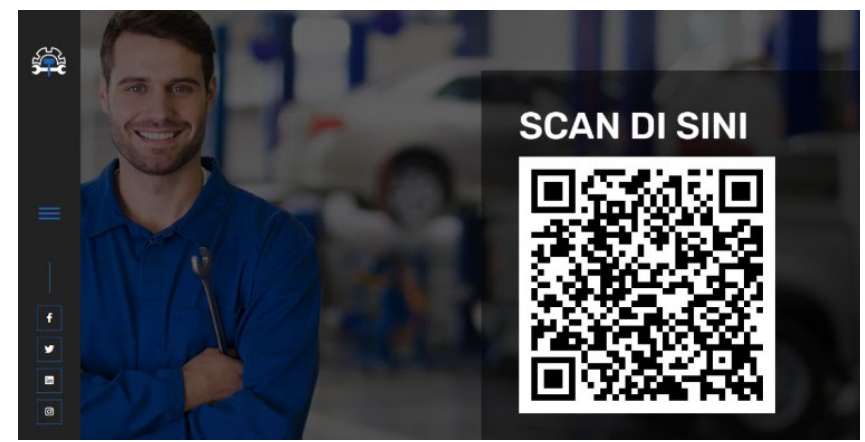

Gambar 9. Tampilan qr code website sistem parkir pada monitor

Pada kondisi ini kamera akan menangkap plat nomor kendaraan pertama untuk dimasukkan pada database sistem parkir. Kemudian pengemudi melakukan pemindaian pada qr code di layar monitor sistem parkir, maka perangkat pengemudi akan terhubung pada website sistem parkir dan memberikan informasi mengenai kode OTP yang akan digunakan oleh pengemudi ketika keluar dari area parkir dan juga informasi mengenai ketersediaan slot parkir kendaraan dengan tampilan website seperti pada gambar 10.

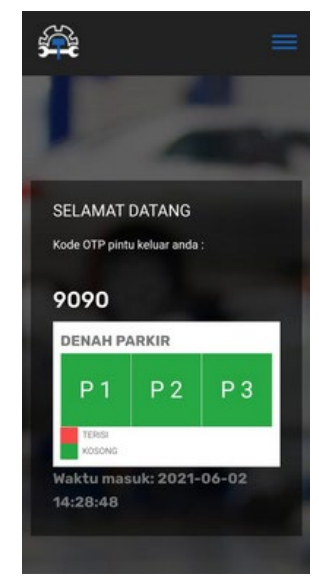

Gambar 10. Tampilan website pada perangkat pengguna setelah melakukan pemindaian qr code 
Setelah itu pengemudi kendaraan dapat membawa kendaraan mereka memasuku area parkir, melalui informasi ketersediaan slot parkir yang telah diberikan pada website, maka kondisi slot parkir adalah seperti gambar 11 .

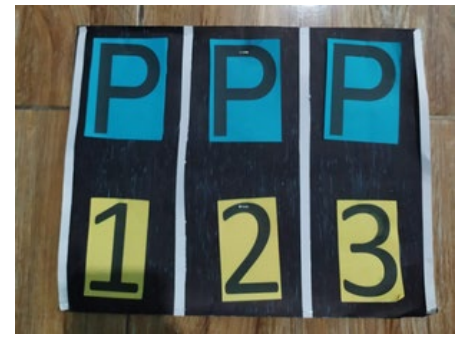

Gambar 11. Kondisi area parkir sebelum kendaraan pertama melakukan parkir

Setelah melalui proses pada pintu masuk area parkir, maka pengemudi dapat melakukan parkir kendaraan pada slot parkir kosong dengan mengisi slot parkir pertama dengan posisi seperti pada gambar 12 .

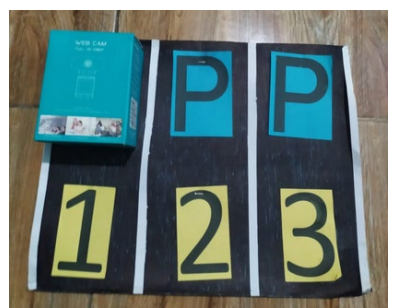

Gambar 12. Kondisi area parkir setelah kendaraan pertama memasuki area parkir

Ketika kendaraan melakukan parkir pada lokasi parkir maka kamera yang digunakan pada area parkir akan menangkap kondisi tersebut, dan melalui kondisi tersebut sistem akan melakukan pembaruan informasi pada website untuk dapat dilihat oleh pengunjung lainnya seperti gambar 13.

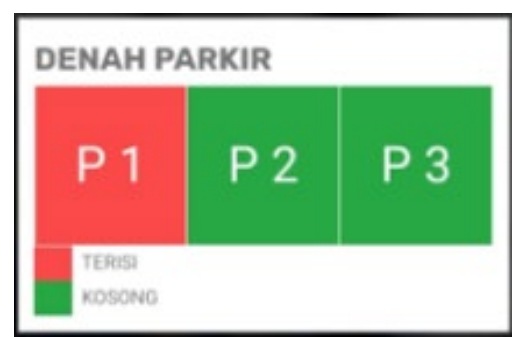

Gambar 13. Tampilan website ketika 1 kendaraan memasuki area parkir

\subsubsection{Pengujian 2 kendaraan memasuki area parkir}

Kondisi lahan parkir setelah kendaraan pertama memasuki lokasi parkir dapat dilihat pada gambar 14.

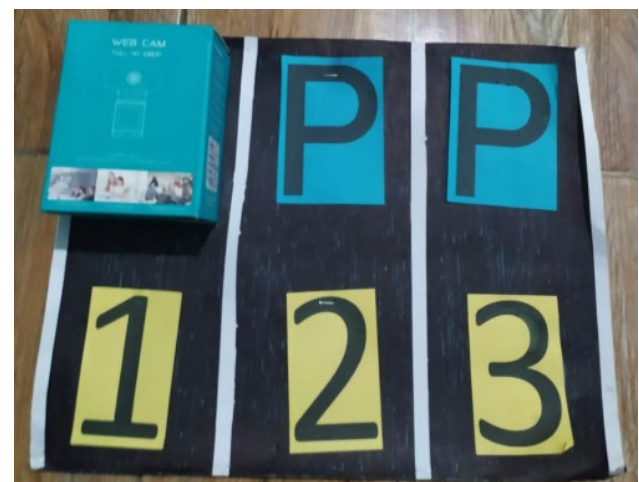

Gambar 14. Lokasi parkir setelah sebuah kendaraan memasuki area parkir 
Sama seperti pengujian 1 ketika kendaraan kedua akan memasuki area parkir maka akan diberikan tampilan monitor yang berisi qr code untuk dilakukan pemindaian oleh pengemudi kendaraan. Pada proses ini kamera akan menangkap informasi berupa plat nomor kendaraan untuk dimasukkan dalam database sistem parkir. Melalui hasil pemindaian $q r$ code tersebut akan tersambung pada website yang memberikan informasi mengenai ketersediaan slot parkir pada website seperti gambar 15 di bawah.

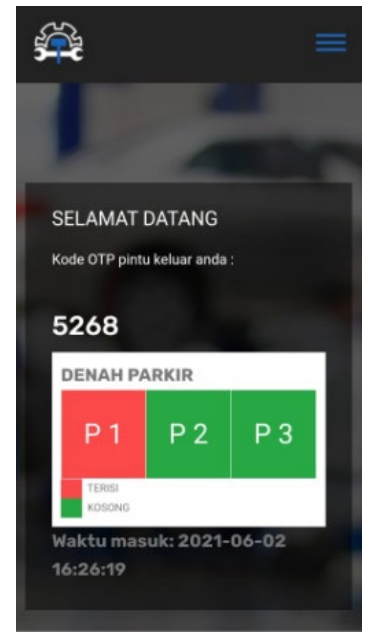

Gambar 15. Tampilan pada website setelah sebuah slot parkir telah terisi

Melalui gambar 15 dapat kita ketahui bahwa slot parkir yang belum terisi hanya 2 bagian dengan slot parkir pertama berisi kendaraan. Oleh karena itu pengemudi dapat memasuki salah satu diantara kedua slot parkir yang masih kosong tersebut. Dalam pengujian kedua, kendaraan mengisi slot parkir ketiga seperti gambar 16 di bawah.

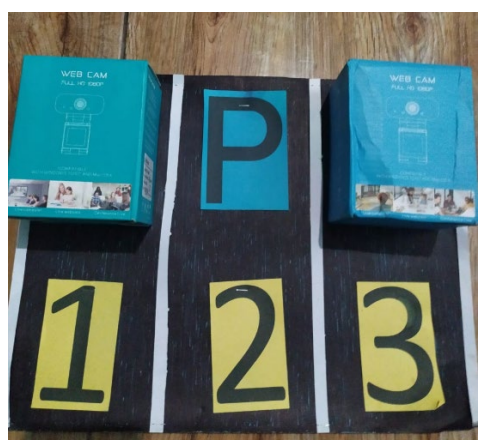

Gambar 16. Lokasi parkir setelah 2 kendaraan memasuki area parkir

Melalui pengisian slot parkir oleh kendaraan kedua seperti gambar 16, maka informasi ketersediaan slot parkir pada website akan diperbarui untuk dapat memberikan informasi terbaru ketika ada kendaraan yang akan memasuki area parkir seperti pada gambar 17.

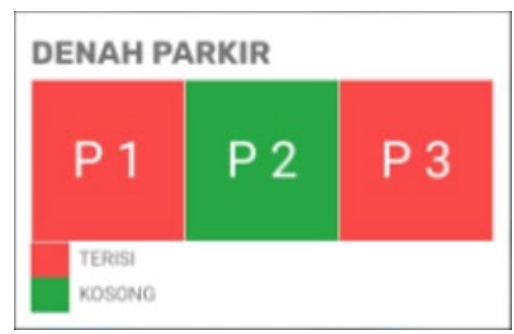

Gambar 17. Tampilan website setelah 2 slot parkir telah terisi

\subsection{Pengujian Keluar Area Parkir}

Ketika kendaraan akan keluar dari area parkir maka hal yang dilakukan adalah membawa kendaraan pada pos keluar area parkir, maka pada monitor akan ditampilkan website sistem parkir yang menampilkan qr code yang dilakukan pemindaian oleh pengemudi kendaraan seperti dibawah. 


\subsubsection{Pengujian kendaraan pertama keluar dari area parkir}

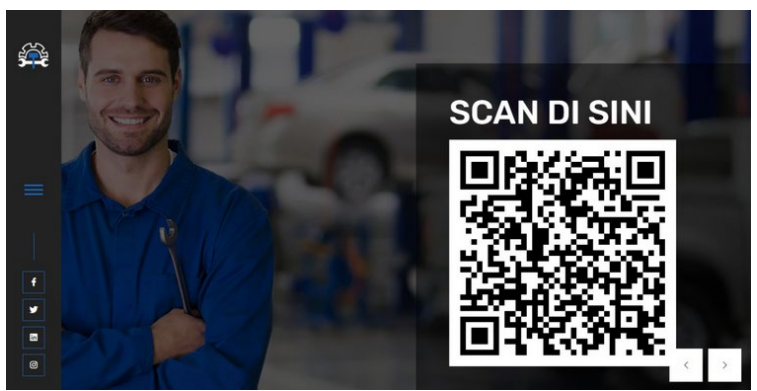

Gambar 18. Tampilan qr code pada website di pintu keluar area parkir

Gambar 18 di atas adalah tampilan website pada monitor pintu keluar area parkir yang akan dipindai oleh pengemudi kendaraan dengan menggunakan smartphone yang dimiliki oleh pengemudi yang akan membawa kendaraan keluar dari area parkir. Pada proses ini kamera akan menangkap informasi berupa plat nomor kendaraan untuk dapat melakukan pencocokan dengan kode OTP yang akan dimasukkan oleh pengemudi kendaraan. Melalui qr code yang ditampilkan pada monitor sistem parkir maka pengemudi kendaraan dapat melakukan pemindaian pada qr code tersebut dan akan terhubung pada website sistem parkir dengan tampilan seperti gambar 19 di bawah.

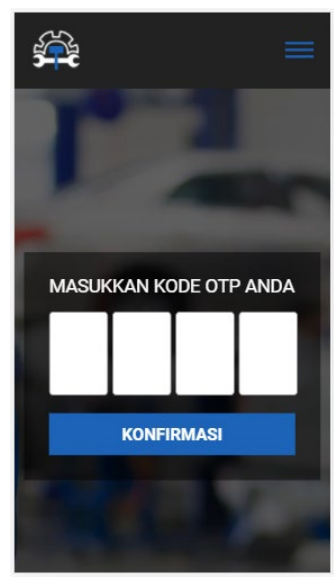

Gambar 19. Tampilan website setelah memindai qr code pada monitor

Melalui tampilan website pada gambar 19, maka pengemudi kendaraan diharapkan memasukkan kode OTP sesuai dengan yang diberikan ketika kendaraan ingin memasuki area parkir. Setelah memasukkan kode OTP dengan benar maka pada website akan tampil antar muka seperti gambar 20.

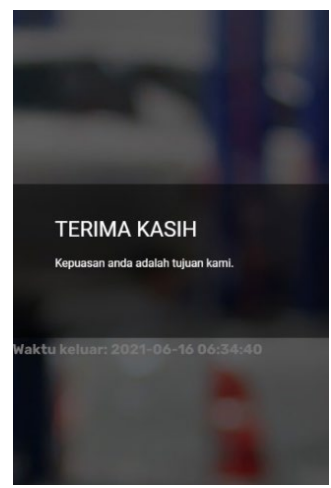

Gambar 20. Tampilan akhir website sistem parkir

Setelah muncul tampilan website sistem parkir seperti diatas, maka pengemudi dapat meninggalkan area parkir. 


\subsubsection{Pengujian kendaraan kedua keluar dari area parkir}

Ketika kendaraan kedua akan meninggalkan lokasi parkir maka hal yang sama dilakukan seperti kendaraan pertama meninggalkan area parkir. Ketika kendaraan berada pada pintu keluar area parkir maka kamera akan menangkap informasi berupa plat nomor kendaraan untuk dilakukan inisialisasi data dalam database sistem parkir. Lalu pengemudi kendaraan melakukan pemindaian $q r$ code pada monitor sistem parkir yang akan menghubungkan pengemudi tersebut pada website sistem parkir. Pada website sistem parkir akan diminta masukan berupa kode OTP yang telah diterima oleh kendaraan kedua pada awal masuk. Sehingga untuk dapat keluar dari area parkir maka pengemudi harus memasukkan kode OTP dengan angka yang diterima ketika kendaraan tersebut memasuki area parkir, jika kendaraan memasukkan kode OTP yang salah maka pada website akan ditampilkan antar muka seperti gambar 21.

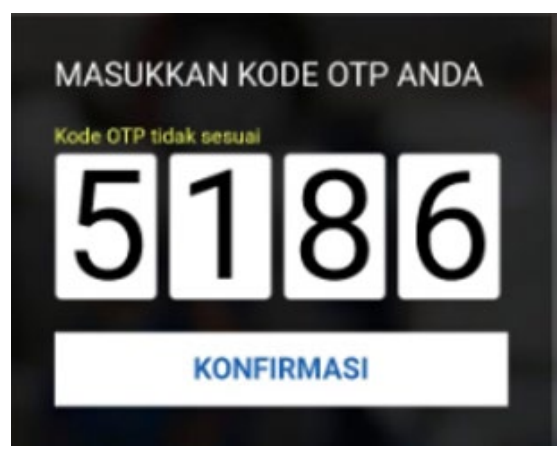

Gambar 21. Tampilan Web untuk masukan kode OTP yang tidak tepat

Ketika hal diatas terjadi maka pada website akan muncul peringatan bahwa kode OTP yang kita masukkan tidak tepat seperti gambar 22, maka pengemudi harus mengulang dalam memasukkan kode OTP yang tepat. Sehingga setelah pengemudi memasukkan kode OTP dengan benar akan muncul ucapan terimakasih yang ditampilkan pada website dan pengemudi dapat membawa kendaraan keluar dari area parkir.

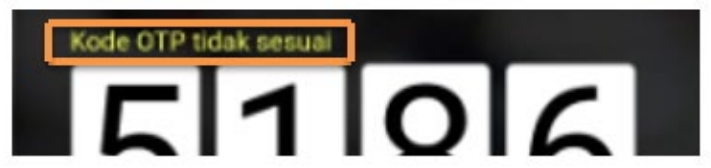

Gambar 22. Peringatan untuk kode OTP yang tidak tepat 


\section{KESIMPULAN}

Setelah melakukan pengimplementasian terhadap Camera-Based Parking System Management Using Raspberry Pi dapat diperoleh kesimpulan yaitu:

1. Implementasi sistem parkir yang telah dibangun digunakan untuk mempermudah kendaraan dalam menemukan slot parkir kosong pada lokasi parkir yang disediakan dengan menggunakan kamera yang dapat melakukan pendeteksian terhadap slot parkir dengan bantuan OCR (optical character recognition).

2. Peningkatan sistem keamanan oleh sistem yang telah dibangun dengan menggunakan kamera yang dapat menangkap informasi karakter dari plat nomor kendaraan dengan bantuan ocr (optical character recognition) serta data tersebut akan dikombinasikan dengan penggunaan qr code yang akan terhubung pada website sistem parkir dan menghasilkan sebuah kode OTP yang dapat digunakan untuk inisialisasi data pada pintu keluar area parkir.

\section{UCAPAN TERIMA KASIH}

Terima kasih kami ucapkan kepada Institut teknologi Del terutama pada program studi Diploma 3 Teknologi Komputer atas semua dukungannya terhadap penyelesaian penelitian ini.

\section{DAFTAR PUSTAKA}

[1] Machsus and Mukafi, "Kajian Kebutuhan Ruang Parkir Pada Mall Galaxy Di Kota Surabaya," Semin. Nas. Apl. Teknol. Prasarana Wil. 2011, no. April, pp. 133-139, 2011, [Online]. Available: https://atpw.files.wordpress.com/2013/03/a19-kajian-kebutuhan-ruang-parkir-di-galaxy-mall-surabaya.pdf.

[2] F. A. IMBIRI, N. TARYANA, and D. NATALIANA, "Implementasi Sistem Perparkiran Otomatis dengan Menentukan Posisi Parkir Berbasis RFId," ELKOMIKA J. Tek. Energi Elektr. Tek. Telekomun. Tek. Elektron., vol. 4, no. 1, p. 31, 2018, doi: 10.26760/elkomika.v4i1.31.

[3] O. Mellolo, "Motorized Vehicle Police Number Plate Recognition," Ejournal Unsrat, vol. 12, no. 1, 2012.

[4] E.-T. A., C.-C. I., N.-M. M., and P.-M. H., "Identity Document Authentication Based on VSS and QR Codes," Procedia Technol., vol. 3, no. March 2014, pp. 241-250, 2012, doi: 10.1016/j.protcy.2012.03.026.

[5] N. S. Hapsari and Y. Fatman, "Implementasi Metode One Time Password pada Sistem Pemesanan Online," vol. 4, pp. 930-939, 2020, doi: 10.30865/mib.v4i4.2195.

[6] A. K. Andi Rosano, Nur Ali Farabi, "PERANCANGAN SISTEM INTERNET BANKING (IBANK) MENGGUNAKAN ONE-TIME-PASSWORD (OTP) UNTUK PENGAMANAN TRANSAKSI (STUDI KASUS BANK MEGA, Tbk)," Bliainiris Éireannach an Dli IdirnáisiúntaThe Irish Yearb. Int. Law, vol. 3, 2021, doi: 10.5040/9781509950904.0012.

[7] I. D. Id and E. Mahdiyah, "Implementasi TOTP ( Time-Based One-Time Password ) Untuk Meningkatkan Keamanan Transaksi E-Commerce,” Konf. Nas. Sist. Inf. 2016, no. August 2016, pp. 11-13, 2016.

[8] A. Zelinsky, Learning OpenCV---Computer Vision with the OpenCV Library (Bradski, G.R. et al.; 2008)[On the Shelf], vol. 16, no. 3. 2009.

[9] D. Z. Putri, D. Puspitaningrum, and Y. Setiawan, "Konversi Citra Kartu Nama ke Teks Menggunakan Teknik OCR dan Jaro-Winkler Distance," J. Teknoinfo, vol. 12, no. 1, p. 1, 2018, doi: 10.33365/jti.v12i1.35.

[10] Y. Andreas, K. Gunadi, and A. N. Purbowo, "Implementasi Tesseract OCR untuk Pembuatan Aplikasi Pengenalan Nota pada Android," J. Infra, vol. 8, no. 1, pp. 2-7, 2020. 